\title{
Application of EWMA chart for monitoring process mean in paper industry
}

\author{
S. Ramesh ${ }^{\mathrm{a}^{*}}$ and B.A. Vasu
}

${ }^{a}$ School of Commerce Studies, Jain (Deemed-to-be) University, Bengaluru, Karnataka 560069, India

\begin{tabular}{l}
\hline C H R O N I C L E \\
\hline Article history: \\
Received: October 29, 2018 \\
Received in revised format: No- \\
vember 19, 2018 \\
Accepted: January 10, 2019 \\
Available online: \\
January 10, 2019 \\
\hline Keywords: \\
Statistical process control \\
Paper machine \\
Bulk density \\
Control Limits \\
EWMA \\
Control chart
\end{tabular}

\begin{abstract}
This paper presents a statistical process control (SPC) chart for variables in a new feature for the paper machine in the paper industry. The traditional control charts like X-bar and R charts may be inadequate sometimes when the process exhibits abnormal situations which could lead to false decisions. When we are interested in detecting small shifts, Exponentially Weighted Moving average (EWMA) control chart provides the correct picture to make right decisions without affecting the process unnecessarily. This study is aimed at designing EWMA control chart in paper manufacturing process.
\end{abstract}

\section{Introduction}

It is not possible to produce all items of a product exactly alike through a production process; a certain amount of natural or inherent variability will exist always. The variability may arise due to the presence of assignable causes or chance causes. Though the chance causes cannot be eliminated, the assignable causes can be found out and eliminated. The use of statistical tools may help to determine the presence of assignable cause and give a warning to make adjustments in the process and avoid the process going out-of-control in near future. The statistical quality control techniques have been tried many times in the paper industry earlier, but there had always been a little bit of difficulty in exactly concluding the presence of assignable causes thus those techniques have been unsuccessful to some extent. There may be several technical reasons for this fact, but the main one is the non-acquaintance with certain control charts, referred to as special, and related to control continuous processes, as in the case of the paper machine. This paper tries to introduce the applicability of Exponentially Weighted Moving average (EWMA) control chart (Gan, 1993; Tang et al., 2018) in paper industry, useful in detecting small shifts in the process.

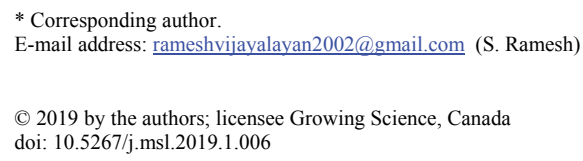




\section{Exponentially weighted moving average (EWMA) control chart}

The exponentially weighted moving average (EWMA) control chart is a good alternative to the Shewhart control chart (Schilling \& Nelson, 1976; Shewhart, 1931; Wheeler, 1996; Liu et al., 2007) when we are interested in detecting small shifts (Braimah et al., 2014; Costa \& Rahim, 2016). The performance of the EWMA control chart is approximately equivalent to that of the cumulative sum control chart (Haq et al., 2018; Simões et al., 2010; You \& Khoo, 2015) and in some ways it is easier to set up and operate (Jones et al., 2001). The exponentially weighted moving average is defined as $z_{i}=\lambda x_{i}+(1-\lambda) z_{i-1}$ where $0<\lambda \leq 1$ is a constant and the starting value (required with the first sample at $I=1)$ is the process target, so that $z 0=\mu_{0}$. Sometimes the average of preliminary data is used as the starting value of the EWMA, so that $z 0=\bar{x}$. The EWMA can be viewed as a weighted average of all past and current observations, it is very insensitive to the normality assumption. It is therefore an ideal control chart to use with individual observations (Montogomery, 1996). The EWMA control chart would be constructed by plotting $z_{i}$ versus the sample number $i$ (or time). The center line and control limits for the EWMA control chart are as follows.

Upper Control Limit $=\quad \mu_{0}+L \sigma \sqrt{\frac{\lambda}{(2-\lambda)}\left[1-(1-\lambda)^{2 i}\right]}$

Center Line $\quad=\quad \mu_{0}$

Lower Control Limit $=\quad \mu_{0}-L \sigma \sqrt{\frac{\lambda}{(2-\lambda)}\left[1-(1-\lambda)^{2 i}\right]}$

The factor $L$ is the width of the control limits, i.e., UCL - LCL. The term $\left[1-(1-\lambda)^{2 i}\right\rfloor$ approaches unity as $i$ gets larger. This means that after the EWMA control chart has been running for several time periods, the control limits will approach steady-state values given by

$$
\begin{array}{lll}
\text { Upper Control Limit } & =\mu_{0}+L \sigma \sqrt{\frac{\lambda}{(2-\lambda)}} \\
\text { Lower Control Limit } & = & \mu_{0}-L \sigma \sqrt{\frac{\lambda}{(2-\lambda)}}
\end{array}
$$

The EWMA control chart is very effective against small process shifts. The design parameters of the chart are the multiple of sigma used in the control limits $(L)$ and the value of $\lambda$. The suggested values of $L$ are between about 2.6 and 2.8 and $\lambda$ is 0.1 (Montgomery, 2007).

\section{EWMA Chart for Bulk Density of Paper produced in a Paper machine}

The bulk density of paper in a day's production various time points is gathered from a paper industry analyzed through EWMA control chart. Choosing $\lambda=0.1, L=2.7, \sigma$ as the average of moving range, and $\mathrm{z}_{0}=1.3325$, the control limits are established and the EWMA control chart produced through Minitab is $\mathrm{z}_{1}=\lambda \mathrm{x}_{1}+(1-\lambda) \mathrm{z}_{0}$, or $\mathrm{z}_{1}=0.1 \times 1.31+(1-0.1) \times 1.3325=1.33025$. Therefore, $z_{1}=1.33025$ is the first value plotted on the control chart in Fig. 1. The second value of the EWMA is $z_{2}=\lambda x_{2}+$ $(1-\lambda) \mathrm{z}_{1}=0.1 \times 1.33+(1-0.1) \times 1.33025=1.33023$. The other values of the EWMA statistic are computed similarly.

The control limits are found using the following equations for period $i=1$. 
$\mathrm{UCL}=\mu_{0}+L \alpha \sqrt{\frac{\lambda}{2-\lambda}\left[1-(1-\lambda)^{2 i}\right]}$

$\mathrm{UCL}=1.3325+2.7 \times 0.01526 \times \sqrt{\frac{0.1}{2-0.1}\left[1-(1-0.1)^{2 \times 1}\right]}=1.3353$

$\mathrm{LCL}=1.3325-2.7 \times 0.01526 \times \sqrt{\frac{0.1}{2-0.1}\left[1-(1-0.1)^{2 \times 1}\right]}=1.3297$

For period $i=2$, the limits are

$\mathrm{UCL}=1.3325+2.7 \times 0.01526 \times \sqrt{\frac{0.1}{2-0.1}\left[1-(1-0.1)^{2 \times 2}\right]}=1.3363$

$\mathrm{LCL}=1.3325-2.7 \times 0.01526 \times \sqrt{\frac{0.1}{2-0.1}\left[1-(1-0.1)^{2 \times 2}\right]}=1.3287$

The limits for other values of $i$ can be calculated accordingly and are shown in Table 1 . The control limits increase in width as $i$ increases from $i=1,2, \ldots$, until they stabilize at the steady-state values given by the following and the control limits are tabulated in Table 2 and chart is depicted in Fig. 1.

$\mathrm{UCL}=\mu_{0}+L \sigma \sqrt{\frac{\lambda}{(2-\lambda)}}=1.3325+2.7 \times 0.010526 \sqrt{\frac{0.1}{(2-0.1)}}=1.3261$,

$\mathrm{LCL}=\mu_{0}-L \sigma \sqrt{\frac{\lambda}{(2-\lambda)}}=1.3325-2.7 \times 0.010526 \sqrt{\frac{0.1}{(2-0.1)}}=1.3389$

Table 1

Computation of Control Limits for EWMA Chart

\begin{tabular}{ccccc}
\hline Bulk Density & CL & EWMA & UCL & LCL \\
\hline 1.31 & 1.3325 & 1.33025 & 1.32970 & 1.33530 \\
1.33 & 1.3325 & 1.33023 & 1.32873 & 1.33627 \\
1.31 & 1.3325 & 1.32820 & 1.32810 & 1.33690 \\
1.34 & 1.3325 & 1.32938 & 1.32765 & 1.33735 \\
1.32 & 1.3325 & 1.32844 & 1.32732 & 1.33768 \\
1.32 & 1.3325 & 1.32760 & 1.32706 & 1.33794 \\
1.32 & 1.3325 & 1.32684 & 1.32686 & 1.33814 \\
1.32 & 1.3325 & 1.32616 & 1.32670 & 1.33830 \\
1.31 & 1.3325 & 1.32454 & 1.32658 & 1.33842 \\
1.31 & 1.3325 & 1.32309 & 1.32648 & 1.33852 \\
1.33 & 1.3325 & 1.32378 & 1.32640 & 1.33860 \\
1.34 & 1.3325 & 1.32540 & 1.32634 & 1.33866 \\
1.35 & 1.3325 & 1.32786 & 1.32629 & 1.33871 \\
1.37 & 1.3325 & 1.33207 & 1.32625 & 1.33875 \\
1.36 & 1.3325 & 1.33487 & 1.32621 & 1.33879 \\
1.34 & 1.3325 & 1.33538 & 1.32619 & 1.33881 \\
1.34 & 1.3325 & 1.33584 & 1.32617 & 1.33883 \\
1.34 & 1.3325 & 1.33626 & 1.32615 & 1.33885 \\
1.34 & 1.3325 & 1.33663 & 1.32614 & 1.33886 \\
1.35 & 1.3325 & 1.33797 & 1.32613 & 1.33887 \\
\hline
\end{tabular}

\section{Table 2}

Control Limits for EWMA Chart

\section{Control limits}

Lower Control Limit

Central Line

Upper Control Limit
Individual values

1.3297

1.3325

1.3389 


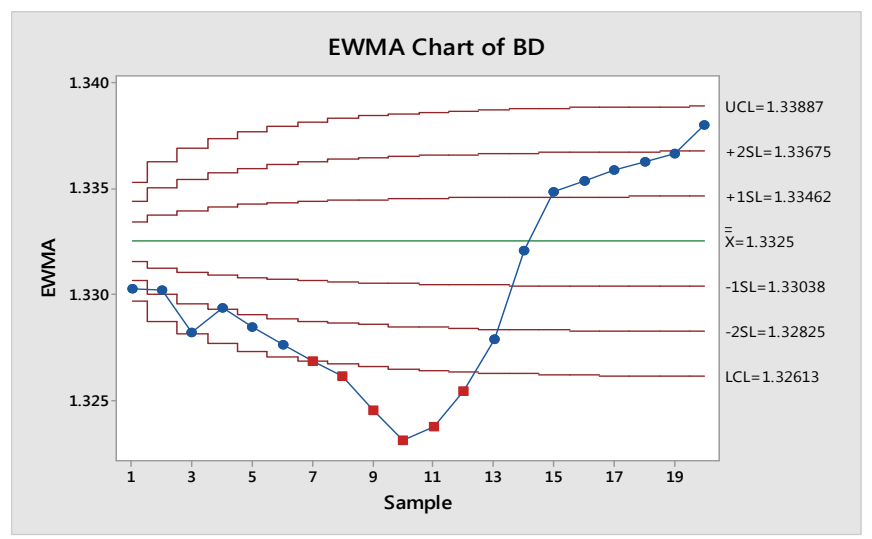

Fig. 1. EWMA Chart

This procedure creates a EWMA individuals chart Bulk density. It is designed to determine whether the data come from a process which is in a state of statistical control. The control chart is constructed under the assumption that the data come from a normal distribution with a mean equal to 1.3325 and a standard deviation equal to 0.01743 . These parameters were estimated from the data. Of the 20 nonexcluded points shown on the charts, six points are beyond the control limits on EWMA chart. It can also be seen from the above chart that there is a downward trend from the fourth point till tenth point and the plots shown an upward trend thereafter. The upward trend alarms that the process may go out of control in the immediate future. Also it is obvious that the most sample points lie beyond 2-sigma limit, indicating that there is a shift in the process. Even though the Cusum charts indicates the presence of 1-sigma and 2-sigma shifts, all the points fall within the 3-sigma limits. However, the EWMA chart detects the shifts in the process and at the same time, it indicates the process out of control, thereby giving signal for some modification in the process. The process parameters were slightly modified on seeing the above control charts and again measurements were taken on bulk density after a week time. The data on Bulk Density were recorded in Table 3.

Table 3

Measurements on bulk density

\begin{tabular}{cccc}
\hline Sample No. & Caliper & Substance & Bulk Density $=\frac{\text { Caliper }}{\text { Substance }}$ \\
\hline 1 & & & 1.34 \\
2 & 100.36 & 75.09 & 1.33 \\
3 & 100.09 & 75.45 & 1.33 \\
4 & 100.09 & 75.36 & 1.34 \\
5 & 100.36 & 74.82 & 1.34 \\
6 & 100.09 & 74.45 & 1.35 \\
7 & 100.18 & 74.45 & 1.34 \\
8 & 100.09 & 74.55 & 1.35 \\
9 & 100.18 & 74.18 & 1.35 \\
10 & 100.00 & 74.09 & 1.33 \\
11 & 100.00 & 73.55 & 1.35 \\
12 & 100.09 & 75.36 & 1.35 \\
13 & 100.73 & 74.64 & 1.34 \\
14 & 101.27 & 75.18 & 1.34 \\
15 & 101.00 & 75.45 & 1.33 \\
16 & 100.82 & 75.45 & 1.33 \\
17 & 101.00 & 76.18 & 1.32 \\
\hline 19 & 101.00 & 75.73 & 1.33 \\
\hline 20 & 101.00 & 76.27 & 1.35 \\
\hline Averages & 100.82 & 75.73 & $\mathbf{1 . 3 4}$ \\
\hline
\end{tabular}

Calculation of EMWA: $\mathrm{z}_{1}=\lambda \mathrm{x}_{1}+(1-\lambda) \mathrm{z}_{0}, \mathrm{z}_{1}=0.1 \times 1.34+(1-0.1) \times 1.34=1.34$. 
Therefore, $z_{1}=1.34$ is the first value plotted on the control chart in Fig. 2 . The second value of the EWMA is equal to $\mathrm{z}_{2}=\lambda \mathrm{x}_{2}+(1-\lambda) \mathrm{z}_{1}=0.1 \times 1.33+(1-0.1) \times 1.34=1.339$. The other values of the EWMA statistic are computed similarly. The control limits are found using the following equations for period $i=1$.

$\mathrm{UCL}=\mu_{0}+L \alpha \sqrt{\frac{\lambda}{2-\lambda}\left[1-(1-\lambda)^{2 i}\right]}$

$\mathrm{UCL}=1.34+2.7 \times 0.008947 \times \sqrt{\frac{0.1}{2-0.1}\left[1-(1-0.1)^{2 \times 1}\right]}=1.3424$

$\mathrm{LCL}=1.34-2.7 \times 0.008947 \times \sqrt{\frac{0.1}{2-0.1}\left[1-(1-0.1)^{2 \times 1}\right]}=1.3376$

For period $i=2$, the limits are

$\mathrm{UCL}=1.34+2.7 \times 0.008947 \times \sqrt{\frac{0.1}{2-0.1}\left[1-(1-0.1)^{2 \times 2}\right]}=1.3432$

$\mathrm{LCL}=1.34-2.7 \times 0.008947 \times \sqrt{\frac{0.1}{2-0.1}\left[1-(1-0.1)^{2 \times 2}\right]}=1.3368$

The limits for other values of $i$ can be calculated accordingly and are shown in Table 4 . The control limits increase in width as $i$ increases from $i=1,2, \ldots$, until they stabilize at the steady-state values given by equation as below.

$\mathrm{UCL}=\mu_{0}+L \sigma \sqrt{\frac{\lambda}{(2-\lambda)}}=1.34+2.7 \times 0.008947 \times \sqrt{\frac{0.1}{(2-0.1)}}=1.3454$

$\mathrm{LCL}=\mu_{0}-L \sigma \sqrt{\frac{\lambda}{(2-\lambda)}}=1.3325-2.7 \times 0.008947 \times \sqrt{\frac{0.1}{(2-0.1)}}=1.3346$

The measurements on bulk density were plotted on a EWMA Chart through Minitab and the resultant graph is appended in Fig. 2.

Table 4

Computation of Control Limits for EWMA Chart

\begin{tabular}{|c|c|c|c|c|}
\hline Bulk Density & CL & EWMA & UCL & LCL \\
\hline 1.34 & 1.34 & 1.34000 & 1.33762 & 1.34238 \\
\hline 1.33 & 1.34 & 1.33900 & 1.33680 & 1.34320 \\
\hline 1.33 & 1.34 & 1.33810 & 1.33626 & 1.34374 \\
\hline 1.34 & 1.34 & 1.33829 & 1.33588 & 1.34412 \\
\hline 1.34 & 1.34 & 1.33846 & 1.33559 & 1.34441 \\
\hline 1.35 & 1.34 & 1.33961 & 1.33538 & 1.34462 \\
\hline 1.34 & 1.34 & 1.33965 & 1.33521 & 1.34479 \\
\hline 1.35 & 1.34 & 1.34069 & 1.33507 & 1.34493 \\
\hline 1.35 & 1.34 & 1.34162 & 1.33497 & 1.34503 \\
\hline 1.36 & 1.34 & 1.34346 & 1.33488 & 1.34512 \\
\hline 1.33 & 1.34 & 1.34211 & 1.33482 & 1.34518 \\
\hline 1.35 & 1.34 & 1.34290 & 1.33476 & 1.34524 \\
\hline 1.35 & 1.34 & 1.34361 & 1.33472 & 1.34528 \\
\hline 1.34 & 1.34 & 1.34325 & 1.33469 & 1.34531 \\
\hline 1.34 & 1.34 & 1.34292 & 1.33466 & 1.34534 \\
\hline 1.33 & 1.34 & 1.34163 & 1.33464 & 1.34536 \\
\hline 1.33 & 1.34 & 1.34047 & 1.33462 & 1.34538 \\
\hline 1.32 & 1.34 & 1.33842 & 1.33460 & 1.34540 \\
\hline 1.33 & 1.34 & 1.33758 & 1.33459 & 1.34541 \\
\hline 1.35 & 1.34 & 1.33882 & 1.33458 & 1.34542 \\
\hline
\end{tabular}

The control limits are shown in Table 5 and the chart is depicted in Fig. 2. 
Table 5

Control Limits for EWMA Chart

\begin{tabular}{lc}
\hline Control limits & Individual values \\
\hline Lower Control Limit & 1.3346 \\
Central Line & 1.3400 \\
Upper Control Limit & 1.3454 \\
\hline
\end{tabular}

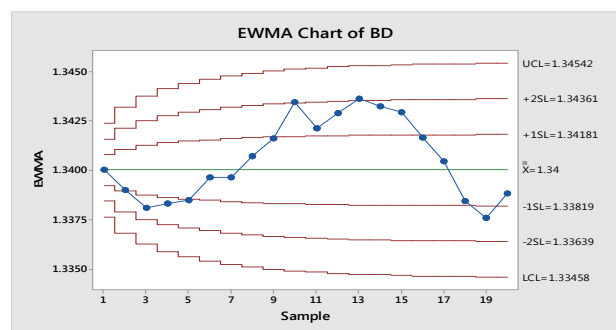

Fig. 2. EWMA chart of bulk density

This procedure creates a EWMA individuals chart Bulk density. It is designed to determine whether the data come from a process which is in a state of statistical control. The control chart is constructed under the assumption that the data come from a normal distribution with a mean equal to 1.34 and a standard deviation equal to 0.01026 . These parameters were estimated from the data. Of the 20 non excluded points shown on the charts, none of the points is beyond the control limits on EWMA chart. It can also be seen from the above chart that almost all the points fall below the 2 -sigma limits, indicating there is no shift in the process.

\section{Conclusion}

The usual text books on statistical quality control do not include the tool of EWMA-chart, it is extremely important in the paper industry to use such a chart to uncover the presence of assignable causes, as sometimes the traditional charts may fail to indicate the same. An ill-selected tool may cause several problems in the quality control and improvement. Thus, using conventional mean and range (x-bar and R) control charts will lead to wrong conclusions. The EWMA control chart is a suitable solution.

\section{References}

Haq, A., Gulzar, R., \& Khoo, M. B. (2018). An efficient adaptive EWMA control chart for monitoring the process mean. Quality and Reliability Engineering International, 34(4), 563-571.

Braimah, O. J., Osanaiye, P. A., Omaku, P. E., Saheed, Y. K., \& Eshimokhai, S. A. (2014). On the use of exponentially weighted moving average (Ewma) control chart in monitoring road traffic crashes. International Journal of Mathematics and Statistics Invention (IJMSI), 2(5), 01-09.

Costa, A. F. B., \& Rahim, M. A. (2006). A single EWMA chart for monitoring process mean and process variance. Quality Technology \& Quantitative Management, 3(3), 295-305.

Gan, F. F. (1993). An optimal design of EWMA control charts based on median run length. Journal of Statistical Computation and Simulation, 45(3-4), 169-184.

Liu, J. Y., Xie, M., Goh, T. N., \& Chan, L. Y. (2007). A study of EWMA chart with transformed exponential data. International Journal of Production Research, 45(3), 743-763.

Jones, L. A., Champ, C. W., \& Rigdon, S. E. (2001). The performance of exponentially weighted moving average charts with estimated parameters. Technometrics, 43(2), 156-167.

Montgomery, D. C. (2007). Introduction to statistical quality control. John Wiley \& Sons.

Schilling, E. G., \& Nelson, P. R. (1976). The effect of non-normality on the control limits of X charts. Journal of Quality Technology, 8(4), 183-188.

Shewhart, W. A. (1931). Economic control of quality of manufactured product. ASQ Quality Press.

Simões, B. F., Epprecht, E. K., \& Costa, A. F. (2010). Performance comparisons of EWMA control chart schemes. Quality Technology \& Quantitative Management, 7(3), 249-261.

Tang, A., Castagliola, P., Sun, J., \& Hu, X. (2018). The effect of measurement errors on the adaptive EWMA chart. Quality and Reliability Engineering International, 34(4), 609-630.

Wheeler, D.J. (1996). Advanced topics in statistical process control. Knoxville, SPC ( $2^{\text {nd }}$ Edition)

You, H. W., \& Khoo, M. B. (2015). A study on a memory type EWMA control chart with unknown process parameters. In Research and Education in Mathematics (ICREM7).

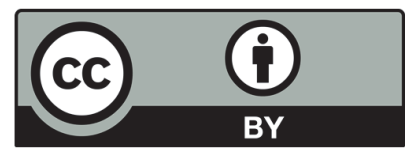

(C) 2019 by the authors; licensee Growing Science, Canada. This is an open access article distributed under the terms and conditions of the Creative Commons Attribution (CC-BY) license (http://creativecommons.org/licenses/by/4.0/). 